WellBeing International

WBI Studies Repository

8-2009

\title{
Veterinary Ethics and Production Diseases
}

Bernard E. Rollin

Colorado State University - Fort Collins, bernard.rollin@colostate.edu

Follow this and additional works at: https://www.wellbeingintlstudiesrepository.org/proveth

Part of the Animal Studies Commons, Bioethics and Medical Ethics Commons, and the Other Veterinary Medicine Commons

\section{Recommended Citation}

Rollin, B. E. (2009, August). Veterinary Ethics and Production Diseases. In Bovine Respiratory Disease Symposium (p. 30).

This material is brought to you for free and open access by WellBeing International. It has been accepted for inclusion by an authorized administrator of the WBI Studies Repository. For more information, please contact wbisr-info@wellbeingintl.org.

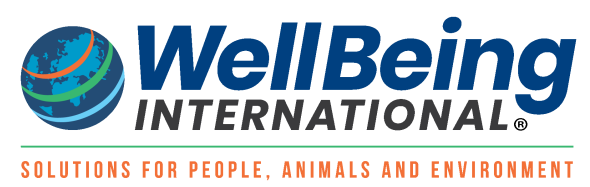




\section{Veterinary Ethics and Production Diseases}

\author{
Bernard E. Rollin, PhD \\ 240 Eddy Hall \\ Colorado State University \\ Ft. Collins, CO 80523-I78I \\ Bernard.Rollin@colostate.edu
}

In various books and articles I have characterized the

I Fundamental Question of Veterinary Medical Ethics as "to whom does the veterinarian owe primary allegiance, animal or owner?"' There are two possible ideal answers to this question. On the one hand, the veterinarian may think of himself or herself as primarily obligated to the animal in the manner of a pediatrician and a child. In this model, though the parents pay the bills, the physician works towards maximizing the child's health and welfare; so too the veterinarian is primarily obligated to the animal's well-being. It is thus not surprising that the profession of pediatrics as a whole, has historically championed child health and welfare, opposing such pathogenic practices as child labor.

On the other hand, the veterinarian may see himself or herself as fundamentally obligated to the client in the manner of a garage mechanic. If a car owner says, " $\$ 1,000$ to fix it? Trash it!", the mechanic complies. Similarly, on this view, the veterinarian exists to implement the client's wishes, (typically economic), regardless of what is in the interests of the animal. In the real world, most veterinarian work in various places along a spectrum between these two extremes, but that does not negate their value as a sound way of articulating ideals.

In my 30 years of involvement with veterinary medicine, I have informally polled thousands of veterinarians regarding their ideal. The vast majority lean towards the pediatrician model and this is not surprising. In the Republic and elsewhere, Plato ingeniously pointed out that the role of any craftsman is to improve the material he or she works their art upon. Thus a goldsmith adds value to unworked gold; a carpenter increases the value of wood by making it into furniture; a sculptor turns stone into art. No such person should ever diminish the value of what he or she works on. If we think of medical professionals as exercising their art to improve the value of the object of their ministrations, plainly such people - physicians or veterinarians - exist to improve what they work on. Hence our horror at Nazi physicians or physicians who collude in torture - they are seen as violating the very nature of their profession. In the same way, veterinarians who set up "hits" on race horses for owners to collect insurance some years ago were viewed with horror and disdain by the public and even by "seen it all" cynical law enforcement personnel. In short, veterinarians may be seen conceptually as existing to improve the health and welfare of animals.

This view of veterinarians is easy to understand regarding companion animals. It is now virtually a cliché that people spend more on these animals than is justified by their market value. As early as 198I, the Wall Street Journal reported on people spending more than six figures on their animals at the pioneering CSU animal cancer center even if the economic value of the animal is $\$ 50$. (Hence the existence of a correlative national thrust on the part of pet animal owners to increase compensation for veterinary malpractice.)

But what of animals whose value is primarily economic, such as laboratory animals or food animals? When I was involved in writing the U.S. federal laws for laboratory animals, the Congress was clear about placing laboratory animal veterinarians as guardians of the well-being of these animals, since these veterinarians were presumed to have one foot in the science camp, but also to be firmly situated as advocates for animal health and wellbeing. (This mandated advocacy goes well beyond what is needed to assure good science.)

What of food animal practitioners? Under traditional, husbandry-based agriculture, the veterinarian's job was to prevent disease, preserve good health, or, if necessary, treat a sick animal if it was cost-effective to do so, or to provide a good death if it was not. To succeed in traditional agriculture to, one must put square pegs in square holes, round pegs in round holes, and create as little friction as possible while doing so. Animal productivity was closely tied to animal health and welfare. A sick or stressed animal could not produce optimally. But all this changed when agriculture became industrialized in the mid-20th century. 
For virtually all of human history, animal agriculture was based foursquare in animal husbandry. Husbandry, derived from the old Norse word "hus/bond" or bonded to the household, meant taking great pains to put one's animals into the best possible environment one could find to meet their physical and psychological natures (which, following Aristotle, I call telos) and then augmenting their ability to survive and thrive by providing them with food during famine, protection from predation, water during drought, medical attention, help in birthing, and so on. Thus, traditional agriculture was roughly a fair contract between humans and animals, with both sides being better off in virtue of the relationship. So powerful is the notion of husbandry, in fact, that when the Psalmist seeks a metaphor for God's ideal relationship to humans, he seizes upon the shepherd in the $23^{\text {rd }}$ Psalm:

The Lord is my shepherd; I shall not want. He maketh me to lie down in green pastures; $\mathrm{He}$ leadeth me beside the still waters; He restoreth my soul.

We wish no more from God than what the husbandman provides for his sheep. In husbandry, a producer did well if and only if the animals did well, so productivity was tied to welfare. Thus, no social ethic was needed to ensure proper animal treatment; only the anticruelty ethic designed to deal with sadists and psychopaths was needed to augment husbandry. Self-interest virtually assured good treatment.

After World War II, this contract was broken by humans. Symbolically, at universities, Departments of Animal Husbandry became Departments of Animal Science, defined not as care, but as "the application of industrial methods to the production of animals" to increase efficiency and productivity. With technological "sanders" - hormones, vaccines, antibiotics, air handling systems, and mechanization - we could force square pegs into round holes and place animals into environments where they suffered in ways irrelevant to productivity. If a 19th century agriculturalist had tried to put 100,000 egg-laying hens in cages in a building, they all would have died of disease in a month; today, such systems dominate.

The new approach to animal agriculture was not the result of cruelty, bad character, or even insensitivity. It developed rather out of perfectly decent, prima facie plausible motives that were a product of dramatic significant historical and social upheavals that occurred after World War II. At that point in time, agricultural scientists and government officials became extremely concerned with supplying the public with cheap and plentiful food for a variety of reasons. In the first place, after the Dust Bowl and the Great Depression, many people in the United States had soured on farming. Second, reasonable predictions of urban and suburban encroachment on agricultural land were being made, with a resultant diminution of land for food production. Third, many farm people had been sent to both foreign and domestic urban centers during the war, thereby creating a reluctance to return to rural areas that lacked excitement; recall the song popular in the 1940s: "How ya gonna keep 'em down on the farm after they've seen Paree?" Fourth, having experienced the specter of starvation during the Great Depression, the American consumer was, for the first time in history, fearful of an insufficient food supply. Fifth, projection of major population increases further fueled concern.

When the above considerations of loss of land and diminution of agricultural labor are coupled with the rapid development of a variety of technological modalities relevant to agriculture during and after World War II and with the burgeoning belief in technology-based economics of scale, it was probably inevitable that animal agriculture would become subject to industrialization. This was a major departure from traditional agriculture and a fundamental change in agricultural core values industrial values of efficiency and productivity replaced and eclipsed the traditional values of "way of life" and husbandry.

The traditional prevalence of husbandry agriculture and the overwhelmingly predominant use of animals in such agriculture more or less assured proper treatment, as harming the animals or failing to put them into circumstances they were biologically suited for would harm their productivity and thus defeat owner selfinterest. The only societal ethic thus needed for animals in such a world was one forbidding deliberate, sadistic, willful, deviant infliction of pain and suffering on an animal - embedded in the anti-cruelty laws, since self-interest is a stronger sanction than law. But when agriculture became industrialized, and society became aware of this change, i.e. that farms were no longer Old McDonald's 
farm and new non-husbandry based uses of animals such as research toxicity testing and teaching had proliferated, it demanded legislated assurance that all animals are wellcared for - hence the proliferation of animal-welfarerelated legislation--2, 100 such bills proposed in the US at the state level in 2004. This new demand changed the social ethic to cover the industrialization of agriculture, which is not cruelty, but still a source of suffering. It is not an accident that the industry soft-pedals the change in agriculture. Perdue poultry ran ads on the urban East Coast for 15 years claiming that,"at Perdue we raise happy chickens" and showing chickens and cows and horses in a farmyard. In the same vein, ads for California cheese depict idyllic cows on pasture, when in fact, as one dairy practitioner told me; they never see a blade of grass.

Current social ethics clearly directs farm animal veterinarians towards the pediatrician model, by virtue of its expectations regarding animal welfare. To understand this point, one must examine the concept of "animal welfare," a concept grossly misunderstood by the intensive agricultural industry and by veterinary medicine.

When one discusses farm animal welfare with industry groups or with the American Veterinary Medical Association, one finds the same response - animal welfare is solely a matter of "sound science". Those of us serving on the Pew Commission, better known as the National Commission on Industrial Farm Animal Production, encountered this response regularly during our dealings with industry representatives. This commission studied intensive animal agriculture in the U.S. (PCIFAP.org). For example, one representative of the Pork Producers, testifying before the Commission, answered that while people in her industry were quite "nervous" about the Commission, their anxiety would be allayed were we to base all of our conclusions and recommendations on "sound science". Hoping to rectify the error in that comment, as well as educate the numerous industry representatives present, I responded to her as follows: "Madame, if we on the Commission were asking the question of how to raise swine in confinement, science could certainly answer that question for us. But that is not the question the Commission, or society, is asking. What we are asking is, ought we to raise swine in confinement? And to this question, science is not relevant". Judging by her "huh", I assume I did not make my point.

Questions of animal welfare are at least partly "ought" questions, questions of ethical obligation. The concept of animal welfare is an ethical concept to which, once understood, science brings relevant data. When we ask about an animal's welfare, when the animal is used by humans, we are asking about what we owe the animal, and to what extent. A document called the CAST report, first published by U.S.Agricultural scientists in the early 1980's, discussed animal welfare. It affirmed that the necessary and sufficient conditions for attributing positive welfare to an animal were represented by the animals' productivity. A productive animal enjoyed positive welfare; a nonproductive animal enjoyed poor welfare (CAST, I 98I).

This notion was fraught with many difficulties. First of all, productivity is an economic notion predicated of a whole operation; welfare is predicated of individual animals. An operation, such as caged laying hens may be quite profitable if the cages are severely over-crowded yet the individual hens do not enjoy good welfare. Second, as we saw, equating productivity and welfare is, to some significant extent, legitimate under husbandry conditions, where the producer does well if and only if the animals do well, and animals are fitted into environments creating as little friction as possible. Under industrial conditions, however, animals do not naturally fit in the niche or environment in which they are kept, and are subjected to "technological sanders" that allow for producers to force animals into unnatural environments - antibiotics, feed additives, hormones, air handling systems - so the animals do not die and produce more and more kilograms of meat or milk. Without these technologies, the animals could not be productive. Before the development of these technologies, producing animals in such systems would have led to sickness and death.

The key point to recall here is that even if the CAST Report definition of animal welfare did not suffer from the difficulties we outlined, it is still an ethical concept. It essentially says "what we owe animals and to what extent is simply what it takes to get them to create profit". This in turn would imply that the animals are well-off if they have only food, water, and shelter, something the industry has sometimes asserted. Even in the early 80 's, however, there were animal advocates and others who would take a very different ethical stance on what we owe farm animals. Indeed, the famous five freedoms articulated in 
Britain by the Farm Animal Welfare view of what we owe animals, when it affirms that:

"The welfare of an animal includes its physical and mental state and we consider that good animal welfare implies both fitness and a sense of well-being. Any animal kept by man, must at least, be protected from unnecessary suffering.

We believe that an animal's welfare, whether on farm, in transit, at market or at a place of slaughter should be considered in terms of 'five freedoms'

I. Freedom from Hunger and Thirst - by ready access to fresh water and a diet to maintain full health and vigor.

2. Freedom from Discomfort - by providing an appropriate environment including shelter and a comfortable resting area.

3. Freedom from Pain, Injury or Disease - by prevention or rapid diagnosis and treatment.

4. Freedom to Express Normal Behavior - by providing sufficient space, proper facilities and company of the animal's own kind.

5. Freedom from Fear and Distress - by ensuring conditions and treatment which avoid mental suffering." (FAWC 1979)

Clearly, the two definitions contain very different notions of our moral obligation to animals (and there is an indefinite number of other definitions). Which is correct, of course, cannot be decided by gathering facts or doing experiments - indeed which ethical framework one adopts will in fact determine the shape of science studying animal welfare.

To clarify: suppose you hold the view that an animal is well-off when it is productive, as per the CAST Report. The role of your welfare science in this case will be to study what feed, bedding, temperature, etc. are most efficient at producing the most meat, milk, or eggs for the least money - much what animal and veterinary science does today. On the other hand, if you take the FAWC view of welfare, your efficiency will be constrained by the need to acknowledge the animal's natural behavior and mental state, and to assure that there is minimal pain, fear, distress and discomfort - not factors in the CAST view of welfare unless they have a negative impact on economic productivity. Thus, in a real sense, sound science does not determine your concept of welfare; rather, your concept of welfare determines what counts as sound science!

The failure to recognize the inescapable ethical component in the concept of animal welfare leads inexorably to those holding different ethical views talking past each other. Thus, producers ignore questions of animal pain, fear, distress, confinement, truncated mobility, bad air quality, social isolation, and impoverished environment unless any of these factors impact negatively on the "bottom line". Animal advocates, on the other hand, give such factors primacy, and are totally unimpressed with how efficient or productive the system may be

A major question obviously arises here. If the notion of animal welfare is inseparable from ethical components, and people's ethical stance on obligations to farm animals differ markedly across a highly diverse spectrum, whose ethic is to predominate and define, in law or regulation, what counts as "animal welfare"? This is of great concern to the agriculture industry, worrying as they do about "vegetarian activists hell-bent on abolishing meat". In actual fact, of course, such concern is misplaced, for the chance of such an extremely radical thing happening is vanishingly small. By and large, however, the ethic adopted in society reflects a societal consensus, what most people either believe to be right and wrong or are willing to accept upon reflection.

Since 1978, I have devoted much of my career to anticipating the emerging social ethic and explaining it to veterinary medicine, industry, and the public. The first point is that this ethic goes well beyond the ethic of anti-cruelty - less than $1 \%$ of animal suffering results from deliberate sadistic cruelty of the sort caused by the cruelty laws. Whatever the source of animal suffering, be it sadism or the quest for scientific knowledge or cheap food, people wish to see it minimized. Secondly, they wish to see the animal's biological and psychological needs and natures (what I call telos,) respected in use. Whereas 40 years ago I visited a zoo where the giraffe's indoor enclosure was such that the animal could not stand up, today such a facility would not last a week. The public rejection of violating animal nature is manifest in laws such as California's proposition 2, rejecting battery cages for 
laying hens, gestation crates for sows, and confined veal in crates, or Arizona's, Oregon's, Florida's, and Colorado's focus on sow stalls. Industry experts affirm that such laws would pass in every state, and I convinced Smithfield farms, the world's largest pork producers, to phase out sow stalls by calling their attention to emerging social ethics for animals, which they verified by surveys and focus groups. The Pew Commission report calls for elimination of high confinement animal agriculture within a decade. And the laboratory animal laws of I 985 I worked on for 10 years prior to their passage demand control of pain and distress in research and teaching, and enrichment of environment for laboratory animals.

In short, this new ethic demands that animals not suffer uncontrolled pain or distress, that their teloi be respected, and that the fairness inherent in the "ancient contract" of husbandry be restored. This ethic provides the ethical content to the concept of animal welfare, and demands that it be guaranteed through the legal system. A Gallup poll conducted in 2003 indicated that $75 \%$ of the U.S. general public wished to see legislated assurance of farm animal welfare. Insofar as societal demands apply to veterinarians, it is clear that the societal ethic reaches the same conclusion we derived from Plato - that veterinarians work to improve the health and welfare of animals of all sorts.

If veterinarians fail to perform this function for animals, they lose their societal respect and indeed violate the internal logic of being a veterinarian as opposed to a mechanic. It is likely for this reason that what I have called "scientific ideology" or the "common sense of science" which derived the knowability of mental or conscious states in animals was so widespread and so different to dislodge. It is a violation of common decency to cause pain, distress, fear, anxiety, discomfort, social isolation to beings who are aware - this is manifestly true for ordinary people. How much the truer would it be for those whose life's work involves caring for animals? It was presumably comforting to scientists as it was to Descartes to believe that what ordinary common sense would call creating pain or other negative feelings in animals was not really what it appeared to be, but simply "nociception" or some other mechanical response. How much the more so would it be to those whose focus is making animals better? Hence there was virtually no acknowledgement of felt pain in science or veterinary medicine. The first U.S. textbooks of anesthesia (Lumb, 1963; Lumb and Jones, 1973) do not mention felt pain or that pain hurts or discuss analgesia

When introducing to Congress what became the 1985 U.S. laboratory animal laws mandating pain control, I was asked by Congress to show that this was not being done without the law. I responded by doing a literature search for "laboratory animal analgesia" and finding no papers, and when broadening the search to "animal analgesia" found only two, one of which said there ought to be papers. (Under pressure of federal law, the number of papers has proliferated, as has use of analgesia.)

It is perhaps something like this ideological defense mechanism that has allowed veterinary medicine to avoid the conclusion of one of my food animal colleagues that production diseases are "the shame of veterinary medicine." For while there is a huge literature on causes, treatment, control, treatment, and nature of production diseases, there is nothing on the ethics thereof. Yet, manifestly, tolerating the very existence of production diseases is a major ethical issue for veterinary medicine.

What are production diseases? They are pathological conditions in an animal resulting exclusively or overwhelmingly from the way the animal is bred for, used, or kept in a production system. While the term originally referred to metabolic diseases such as hypocalcemia in dairy cattle, it is more reasonably deployed to cover a variety of diseases - metabolic infections, genetic, environmental and even behavioral. Production diseases are largely a result of the intensification of agriculture. As one book puts it, "Common production diseases that affect dairy cattle such as ketosis, fatty liver, and displaced abomasums, rarely, if ever, affect beef cows on pasture." (Drackley, 2006). As one early discussion put it: "Production disease is a man-made problem; it consists of a breakdown of the various metabolic systems of the body under the combined strain of high production and modern intensive husbandry." (Payne, 1972) Shortly thereafter, infectious and other diseases supplemented metabolic diseases in the understanding of production diseases. 
There is an indefinite number of such diseases. Many are caused at least in part by univocal breeding exclusively for production, such as lameness and reproductive problems in dairy cattle, mastitis in dairy cattle, and skeleto-muscular problems in broiler chickens. Others are caused in part by crowding, such as tail-biting. Others came from failure of the environment in which they are kept to respect the animals' biological nature, such as foot and leg problems in cattle and swine, where animals evolved for pasture are kept on concrete. Others such as cannibalism and feather pecking in laying chickens and tail-biting in swine are also caused by extreme confinement not allowing for escape and establishment of normal dominance hierarchies. Still others result from unnatural feeding practices, such as liver and rumenal abscesses in feed-lot cattle. And while BRD or shipping fever is multi-factorial, a major part of its etiology is the stress of confinement and transport and mixing of cattle. Pastoral beef cattle slaughtered near home would not show current rates of shipping fever. Much of shipping fever could be prevented by changing genetics, but this would result in lower productivity so it is not done. It is fair, then, to attribute many production diseases to the industrialization of agriculture, and the concomitant emphasis on production over all else, and the tendency to put the animals into unnatural environments or unnatural feeding regimes (cf. Bovine Spongiform Encephalopathy or BSE.)

Let us look more closely at a few representative production diseases.

The most striking example I can think of occurs in the use of geese for production of pate de foi gras. (This disease predates the industrialization of agriculture.) The geese are force-fed to deliberately produce the disease known as fatty liver for the sake of creating a soft pate. It is indicative of the neglect of such diseases from an ethical point of view that AVMA has failed to speak against the system. Even more indicative is the fact that the 350 small print pages comprising the 110 papers in the standard text, Production Diseases in Farm Animals, not one chapter, paragraph or even sentence is devoted to ethics. (Joshi and Herdt, 2006)

As mentioned earlier, another exazmple is provided by rumenal and liver abscesses in fed cattle. Such abscesses are a direct result of feeding too "hot" a grain diet, with insufficient roughage. They occur in 12 to $32 \%$ of fed cattle. This disease leads to condemnation of 5 to $10 \%$ of carcass livers at slaughter. It also affects the animals' general health. (Nagaraja and Chengappa, 1998) (The percentage would be much higher without tylosin). The obvious answer is to modify the diet. But, producers make more money with the grain diet even with the lost carcasses than they would if they fed more grass. This is a classic example of productivity failing to assure welfare!

And the subject of this conference represents yet another example, as we just mentioned, since a major factor in the advent of this disease is humanly-caused stress. Other relevant manageable factors are crowding (which facilitates transmission) and other stressful living conditions combined with universal cow genetic selection for production. A list of other production disease in cattle is a dismal indictment of modern production - ketosis, metritis, hypocalcaemia, laminitis, dystocia, mastitis, foot and leg problems, reproductive problems, displaced abomasums, fatty liver, retained placenta, reproductive failure, and digital dermatitis. An univocal selection for production has created osteoporosis and cloacal prolapse in egg-laying hens, skeletal disorders in chickens and turkeys, flip-over syndrome in broilers and, historically, porcine stress syndrome in swine. (Though the genetic component has been eliminated, the disease is still prevalent due to environmental factors.)

What are we to say of production diseases from an ethical point of view? No one could possibly question that, regardless of one's definition of welfare, good health is surely presuppositional to good welfare, and that production diseases are thus inimical to good welfare. And if the essence of veterinary medicine is to act like a physician for animals, it clearly cannot accept treating production diseases which are preventable by changing the system of production. Often in the swine industry, and regularly in the poultry and egg industries, individual sick animals may not even be treated- "herd health" has superseded treating individuals. It is conceptually and morally impossible for veterinarians to accept systems that make animals sick, rather than trying to change the system. And we know that this can be done because these diseases were of far less or no importance prior to the advent of industrial agriculture. (To be fair, there were other diseases prevalent, such as parasites in swine raised outdoors. But such diseases were nowhere near as serious or prevalent as current production diseases. 
Furthermore, protection from parasites does not justify wholesale violation of a pig's telos.) I am not saying that veterinarians should fail to treat sick animals that are created by current production systems; in fact they need to add more treating of individual animals to the current emphasis on herd health. Most swine veterinarians do not treat individual animals on large swine operations this work is assigned to stockpeople who may not be adequately trained in diagnosis and treatment.. The same is true in broilers and layers. But I am saying veterinary medicine should not accept the status quo and band-aid pathogenic systems. As my friend Tim Blackwell, chief swine veterinarian for the province of Ontario puts it, "We are obligated to treat (band-aid) the diseases, but we are not obligated to defend the systems that created these diseases."

What should be done is for veterinarians, with the support of the new social ethic, to pioneer in the redesign of livestock production systems. Presuppositional to such new systems must be the health and welfare of the animals. When that is assured as a foundation, one can go on to try to maximize profit. (Note that a total emphasis on production does not necessarily entail profitability, as for example has been shown in the dairy and swine industries.)

Veterinarians alone, of course, cannot change these pathogenic systems. But they can work to convince producers that society will not tolerate these systems much longer, and can lead in finding economically viable modifications and alternatives. And organized veterinary medicine must stop being the cheer-leaders for current systems-witness AVMA saying that there are no better and worse sow housing systems at the same time as Smithfield eliminated gestation crates.

It is possible that such reform may result in higher food prices. This is not necessarily the case - group housing of swine costs $50 \%$ for capitalization of what gestation crates cost. But it is certainly likely as one attempts to restore good husbandry. So what? Americans spend only some $10 \%$ of their income for food - Europeans spend double that. Recent activity on behalf of animal welfare such as Proposition 2 in California indicates the fact that public concern is not mitigated by threats of increased prices - the egg industry lost soundly despite that ploy. As the Federation of European Veterinarian affirmed over 20 years ago, higher food prices are a small price to pay to assure that the animals we consume have decent lives. The public was not deterred from demanding law protecting the interests of laboratory animals by dire threats from the research community that such laws (i.e. the laws of I 985 that I helped draft and defend) would prevent discoveries that cure sick children. (In fact the opposite is the case.)

When one couples the existence of production disease with the other costs of industrial agriculture environmental despoliation, loss of sustainability, animal and human disease, antibiotic resistance of pathogens, the loss of small farms and farm communities, damage to human and animal health, cheap food does not seem so cheap; many of the costs are in fact externalized to consumers. It is not a wonder that the PEW commission on which I served for almost three years recommended the abolition of high confinement industrial agriculture within 10 years, and was greeted by much support from the press. People realize that these problems must be solved for the sake of a "livable future." One of Pew's conclusions is that so-called "cheap food" is only cheap at the register, while hidden costs are regularly "externalized," i.e. charged to the public in hidden ways.

Furthermore, I have sufficient faith in American ingenuity to believe that agriculture can be recrafted to solve the above problems and still provide food at a reasonable price. We have never in fact tried - the last 50 years have witnessed excessive emphasis on productivity. It is very likely that agriculture can and will rise to the challenge of reinvesting itself taking cognizance of the other values hitherto neglected. It is fitting that veterinarians, who should be guardians of animal health and welfare, lead this change. If the industry fails to adjust, it risks loss of autonomy and freedom as the public acts to rectify what it finds abhorrent, but does not fully understand. As the history of animal husbandry demonstrates, we raised animals for 1000 years viewing disease as the enemy, not as an ally in the quest for profit. 


\section{Acknowledgement}

I am grateful to Dr.Tim Blackwell of OMAFRA for dialogue.

\section{References}

Council for Agricultural Science and Technology (CAST, 198I). Scientific Aspects of the Welfare of Food Animals, Report no. 9I, November.

Drackley JK (2006). Advances in transition cow biology: new frontiers in production diseases. In Joshi $\mathrm{N}$ and $\mathrm{Herdt} \mathrm{TH}$ (Eds.) Production Diseases in Farm Animals. Wageningen:Wageningen Academic Publishers.

Gallup (2003). Farm Animal Welfare Council 1979. The Five Freedoms (www.fawc.uk.org) Gallup poll 2003. www.gallup.org

Joshi N and Herdt TH, eds (2006). Production Diseases in Farm Animals. Wageningen:Wageningen Academic Publishers. Lumb WV (1963). Small Animal Anesthesia. Philadelphia: Lea \& Febiger.

Lumb WV, Jones EW (1973). Veterinary Anesthesia. Philadelphia: Lea \& Febiger.

Nagaraja TG and Chengappa MM (1998). Liver abscesses in feedlot cattle: a review. Journal of Animal Science 76:287298.

Payne JM (1972). Production disease. Journal of the Royal Agricultural Society of England vol:I33.

Rollin BE (1995). Farm Animal Welfare. Ames, lowa: lowa State University Press. 